\title{
Retuning the Catalytic Bias and Overpotential of a [NiFe]- Hydrogenase via a Single Amino Acid Exchange at the Electron Entry/Exit Site
}

Hope Adamson, ${ }_{\dagger}^{\dagger}$ Martin Robinson, ${ }^{\ddagger}$ John J. Wright, ${ }^{\S}$ Lindsey A. Flanagan, ${ }^{\dagger}$ Julia Walton, ${ }^{\dagger}$ Darrell Elton, ${ }^{\|}$ David J. Gavaghan, ${ }^{\ddagger}$ Alan M. Bond, ${ }^{\perp}$ Maxie M. Roessler, ${ }^{\S}$ and Alison Parkin ${ }^{*}{ }^{\dagger}$ (1)

${ }^{\dagger}$ Department of Chemistry, University of York, Heslington, York YO10 5DD, U.K.

${ }^{\ddagger}$ Department of Computer Science, University of Oxford, Oxford, OX1 3QD, U.K.

${ }^{\S}$ School of Biological and Chemical Sciences, Queen Mary University of London, Mile End Road, London, E1 4NS, U.K.

"Department of Engineering, School of Engineering and Mathematical Sciences, La Trobe University, Melbourne, Victoria 3086, Australia

${ }^{\perp}$ School of Chemistry, Monash University, Clayton, Victoria 3800, Australia

Supporting Information

ABSTRACT: The redox chemistry of the electron entry/exit site in Escherichia coli hydrogenase-1 is shown to play a vital role in tuning biocatalysis. Inspired by nature, we generate a HyaA-R193L variant to disrupt a proposed Arg-His cation $-\pi$ interaction in the secondary coordination sphere of the outermost, "distal", iron-sulfur cluster. This rewires the enzyme, enhancing the relative rate of $\mathrm{H}_{2}$ production and the thermodynamic efficiency of $\mathrm{H}_{2}$ oxidation catalysis. On the basis of Fourier transformed alternating current voltammetry measurements, we relate these changes in catalysis to a shift in the distal $\left[\mathrm{Fe}_{4} \mathrm{~S}_{4}\right]^{2+/ 1+}$ redox potential, a previously experimentally inaccessible parameter. Thus, metalloenzyme chemistry is shown to be tuned by the second coordination sphere of an electron transfer site distant from the catalytic center.
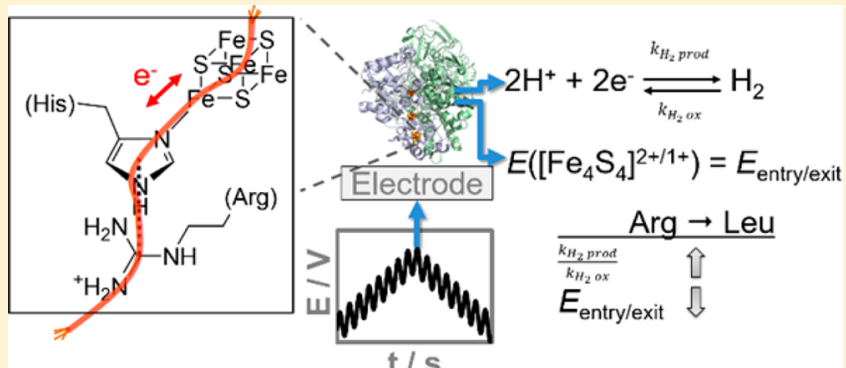

$\mathrm{t} / \mathrm{s}$

\section{INTRODUCTION}

Hydrogenases are remarkable biological catalysts, with the ability to interconvert $\mathrm{H}_{2}$, protons, and electrons $\left(\mathrm{H}_{2} \leftrightarrows 2 \mathrm{H}^{+}+\right.$ $\left.2 \mathrm{e}^{-}\right)$at rates comparable to platinum, but using abundant-metal active sites of iron or nickel and iron. ${ }^{1}$ These enzymes are therefore studied with the hope of both understanding microbial metabolism and discovering sustainable catalysts to underpin a $\mathrm{H}_{2}$-energy economy. The $\mathrm{O}_{2}$-tolerant membranebound $[\mathrm{NiFe}]$-hydrogenases $(\mathrm{MBHs})$, capable of sustained catalysis in $\mathrm{O}_{2}$, have garnered the most significant interest (Figure 1a). Reprogramming the reactivity of such $[\mathrm{NiFe}]$ hydrogenases is desirable because there is not a naturally occurring enzyme that is both active in $\mathrm{O}_{2}$ and capable of highefficiency catalysis and rapid $\mathrm{H}_{2}$ production. This is particularly clear in catalytic protein film voltammetry experiments, in which hydrogenase is adsorbed onto the surface of an electrode and catalytic current is measured as a function of potential, fingerprinting both the catalytic bias (ratio of $\mathrm{H}_{2}$ oxidation to $\mathrm{H}_{2}$ production current) and the potential at which catalysis commences (Figure $1 \mathrm{~b}){ }^{2,3}$ The $[\mathrm{NiFe}]$-hydrogenases that are ideal bidirectional $\mathrm{H}_{2}$ electrocatalysts, displaying high $\mathrm{H}_{2}$ production and oxidation turnover rates, are inactivated by $\mathrm{O}_{2}\left(\mathrm{O}_{2}\right.$-sensitive, e.g., Escherichia coli hydrogenase-2). ${ }^{2,4,5}$
Conversely, the $\mathrm{O}_{2}$-tolerant $\mathrm{MBHs}$ are poor $\mathrm{H}_{2}$-producing catalysts and require an additional thermodynamic driving force (overpotential) to initiate $\mathrm{H}_{2}$ oxidation at $\mathrm{pH}>5$, e.g., Escherichia coli hydrogenase-1 (E. coli Hyd-1). ${ }^{2,4,5}$ Therefore, despite $[\mathrm{NiFe}]$-hydrogenases being naturally expressed by photosynthetic microbes, ${ }^{6}$ sustained solar water-splitting to yield $\mathrm{H}_{2}$ is impossible using native enzymes, and a molecular understanding of the factors that control catalytic bias and overpotential is required.

Crystal structures have been resolved for four $\mathrm{O}_{2}$-tolerant $\mathrm{MBHs}$, including the subject of this study, E. coli Hyd-1. ${ }^{7-12}$ The electron entry/exit site is the "distal" $\left[\mathrm{Fe}_{4} \mathrm{~S}_{4}\right]$ cluster which sits at the end of a chain of three iron-sulfur clusters that span the small (approximately $30 \mathrm{kDa}$ ) protein subunit and transfer electrons between the surface of the protein and the bimetallic $\mathrm{NiFe} \mathrm{H}_{2}$-activating site that is buried in the large (approximately $60 \mathrm{kDa}$ ) protein subunit (Figure 1a). ${ }^{7-12}$ Soluble and membrane-bound $\mathrm{O}_{2}$-sensitive $[\mathrm{NiFe}]$-hydrogenases have this same overall structure; ${ }^{13-16}$ in particular, the NiFe centers are identical, and the surrounding architecture is remarkably

Received: April 10, 2017

Published: July 12, 2017 


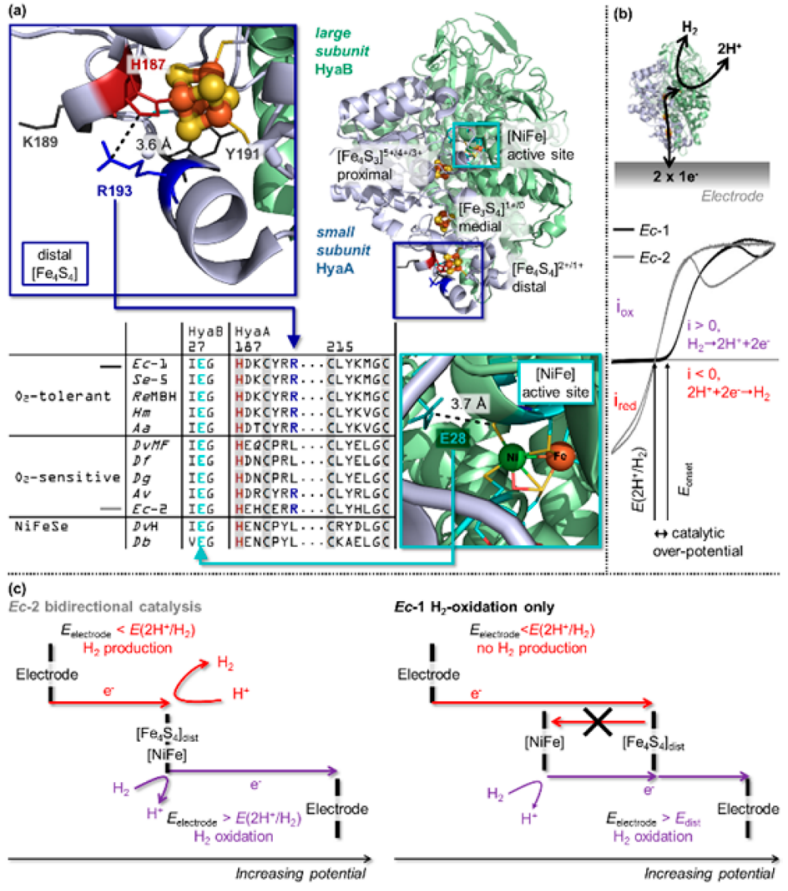

Figure 1. (a) E. coli hydrogenase-1 structure (PDB 5A4I) with detail of position of HyaB-E28 relative to active site and HyaA-H187, HyaAR193, HyaA-K189, and HyaA-Y191 relative to the distal cluster. The sequence alignment ( $E$. coli Hyd-1 numbering) highlights the conserved nature of E28 in the HyaB protein in E. coli Hyd-1 (Ec1), Salmonella enterica Hyd-5 (Se-5), Ralstonia eutropha $\mathrm{MBH}$ (ReMBH), Hydrogenovibrio marinus (Hm), Aquifex aeolicus (Aa), Desulfovibrio vulgaris Miyazaki F (DvMF), Desulfovibrio fructosovorans $(D f)$, Desulfovibrio gigas $(D g)$, Allochromatium vinosum $(A v)$, E. coli Hyd-2 (Ec-2), Desulfovibrio vulgaris Hildenborough $(D v \mathrm{H})$, and Desulfomicrobium baculatum $(D b) \mathrm{NiFe}$ or $\mathrm{NiFeSe}$ hydrogenases. Also indicated are the distal cluster ligands (gray shading), with dark red text highlighting HyaA-H187 and dark blue text highlighting HyaA-R193. (b) Cartoon depiction of enzyme on electrode and resultant comparative direct current voltammogram traces for either an $\mathrm{O}_{2}$-tolerant hydrogenase $(E c-1)$ or an $\mathrm{O}_{2}$-sensitive hydrogenase $(E c-2)$ at $\mathrm{pH}>5$ and under a $\mathrm{H}_{2}$ atmosphere. The difference in catalytic bias is quantified by the ratio of oxidation current, $i_{\mathrm{ox}}$, to reduction current, $i_{\text {red }}$. The onset potential of $\mathrm{H}_{2}$ oxidation catalysis, $E_{\text {onset }}$ coincides with the reduction potential for the proton $/ \mathrm{H}_{2}$ couple $\left(E\left(2 \mathrm{H}^{+} / \mathrm{H}_{2}\right)\right)$ for an $\mathrm{O}_{2}$-sensitive hydrogenase, but there is an overpotential requirement for $\mathrm{O}_{2}$-tolerant hydrogenases. (c) Pictorial representation of how simple thermodynamic considerations suggest that unidirectional $\mathrm{H}_{2}$ oxidation-only catalysis results when $E_{\text {dist }} \gg \mathrm{E}\left(2 \mathrm{H}^{+} / \mathrm{H}_{2}\right)$. Thermodynamically spontaneous electron transfer can proceed only from left to right; thus electrons can be pushed into the enzyme when $E_{\text {electrode }}<$ $E_{\text {dist }}$ or pulled out of the enzyme when $E_{\text {dist }}<E_{\text {electrode }}$ (Left) When $E_{\text {dist }}=E\left(2 \mathrm{H}^{+} / \mathrm{H}_{2}\right)$, this results in bidirectional catalysis. (Right) When $E_{\text {dist }} \gg E\left(2 \mathrm{H}^{+} / \mathrm{H}_{2}\right), \mathrm{H}_{2}$ production is prevented by the nonspontaneous movement of electrons from the distal cluster to the active site.

similar. A fully conserved large subunit Glu is found close to the $\mathrm{NiFe}$ center in all structures (Figure 1a), and replacement with a nonacidic residue disables catalysis in a number of $[\mathrm{NiFe}]$ hydrogenases, ${ }^{17-19}$ suggesting a highly conserved proton transfer relay and mechanism for active site chemistry. Therefore, the $\mathrm{NiFe}$ site is unlikely to be the control center for differences in the $\mathrm{H}_{2}$ reactivity of $\mathrm{O}_{2}$-tolerant and $\mathrm{O}_{2}$ sensitive $[\mathrm{NiFe}]$-hydrogenases, in contrast with classical models of enzyme catalysis, which ascribe substrate reactivity and energetics solely to the local environment of the active site.

$A$ unique $\left[\mathrm{Fe}_{4} \mathrm{~S}_{3}\right]$ proximal cluster is required for $\mathrm{O}_{2}$ tolerance in $\mathrm{MBHs}{ }^{8-12,20,21}$ and along with the $\left[\mathrm{Fe}_{3} \mathrm{~S}_{4}\right]$ medial cluster, $^{22}$ these centers provide electrons for the reduction of inhibitory $\mathrm{O}_{2}$ to water at the $\mathrm{NiFe}$ site, indicating that iron sulfur cluster chemistry can control active site reactivity. However, in variants with diminished $\mathrm{O}_{2}$ tolerance due to proximal and medial cluster ligand changes, there is no change in the catalytic reversibility of the enzyme. ${ }^{12,20-22}$ Instead, an electrocatalytic model by Hexter et al. proposes that both the catalytic bias and overpotential of multicenter redox enzymes are controlled by the redox potential of the electron entry/exit site, the distal cluster in [NiFe]-hydrogenases. ${ }^{5,23}$ Decoding to what extent the redox potential of one electron transfer center can control catalytic reversibility and efficiency is important because hydrogenases are just one example of a large class of electron-relay-containing "wired" metalloenzymes that redoxactivate notoriously stable small molecules such as $\mathrm{N}_{2}, \mathrm{H}_{2} \mathrm{O}$, and $\mathrm{CO}_{2}$.

The tantalizingly simple conclusion of the Hexter model is that complete catalytic reversibility is predicted when the potential of the distal cluster $\left[\mathrm{Fe}_{4} \mathrm{~S}_{4}\right]^{2+/ 1+}$ redox transition, $E_{\text {dist }}$ matches that of the substrate product couple, $E\left(2 \mathrm{H}^{+} / \mathrm{H}_{2}\right)$., 23 Conversely, a mismatch in potentials results in an overpotential and a concurrent catalytic bias. ${ }^{5,23}$ In the case of a substantial potential difference the distal cluster essentially acts as an electronic diode, enforcing unidirectional electron flow. ${ }^{5,23}$ This is most readily illustrated by a horizontal potential scale diagram, as shown in Figure 1c. Rapid, thermodynamically favorable electron transfer occurs when the reduction potential of the electron donor is more negative than that of the electron acceptor. Thus, it is predicted that the essentially unidirectional, $\mathrm{H}_{2}$-oxidizing-only catalysis of $\mathrm{O}_{2}$-tolerant $\mathrm{MBHs}$ at $\mathrm{pH}>5$ arises because $E_{\text {dist }}>E\left(2 \mathrm{H}^{+} / \mathrm{H}_{2}\right)$ over this $\mathrm{pH}$ range. The enhanced catalytic reversibility of $E$. coli $\mathrm{Hyd}-1$ at $\mathrm{pH}<5$ is interpreted as evidence that the potentials of $E_{\text {dist }}$ and $E\left(2 \mathrm{H}^{+} /\right.$ $\mathrm{H}_{2}$ ) converge at low $\mathrm{pH}^{24}$ Equally, a catalytic bias toward reduction catalysis $\left(\mathrm{H}_{2}\right.$ production) and an overpotential requirement for this activity would be attributed to $E_{\text {dist }}<$ $E\left(2 \mathrm{H}^{+} / \mathrm{H}_{2}\right) .{ }^{5,23}$ In contrast, on the basis of their more complex electrocatalytic model of hydrogenase activity, Léger and coworkers suggest that $E_{\text {dist }}$ will only influence the catalytic reversibility, not completely control it, due to the different nature of the rate-limiting steps in $\mathrm{H}_{2}$ production and oxidation and the effects of intramolecular electron transfer within the enzyme. $^{25,26}$ Comparison of the two models is not possible because there is no experimental measurement of $E_{\text {dist }}$ for $E$. coli Hyd- $1,{ }^{27}$ and there have been no [NiFe]-hydrogenase distal cluster variants with a retuned $E_{\text {dist }}$.

There is a wealth of literature describing how retuning the noncovalent interactions of residues in the second coordination sphere of protein electron transfer centers can have a substantial impact on the redox potential. ${ }^{28,29}$ In many $\mathrm{O}_{2}$ sensitive $[\mathrm{NiFe}]$-hydrogenases, a Leu residue sits at the apex of the helix between the surface of the protein and the distal cluster His ligand (Figure 1a and Supplementary Figure 1). ${ }^{13-16}$ In contrast, sequence comparisons and structural analyses reveal that in all $\mathrm{O}_{2}$-tolerant hydrogenases ${ }^{7-12}$ a conserved Arg occupies this position, and it is close enough to the distal cluster His ligand for a cation $-\pi$ interaction to persist (C $\zeta$ to $\mathrm{N} \tau$ from 3.3 to $3.7 \AA$ ); that is, there should be an electrostatic attraction between the $\pi$ electron system of His 
(a) aperiodic dc $100 \% \mathrm{H}_{2}$

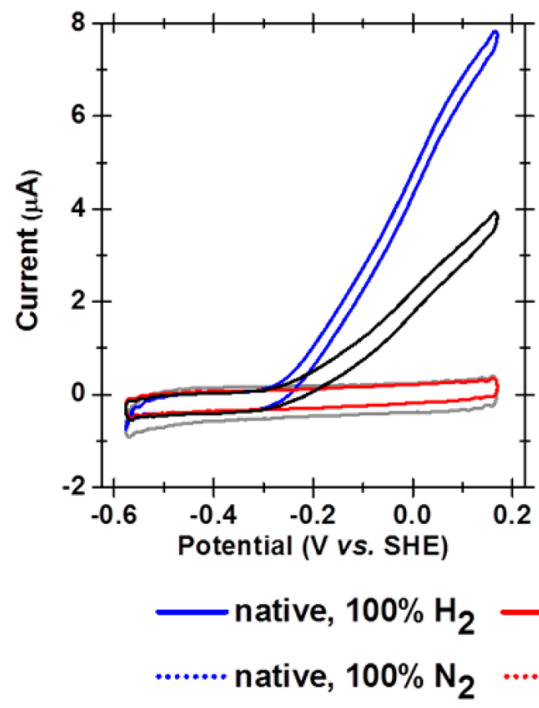

(b) aperiodic dc $100 \% \mathrm{~N}_{2}$

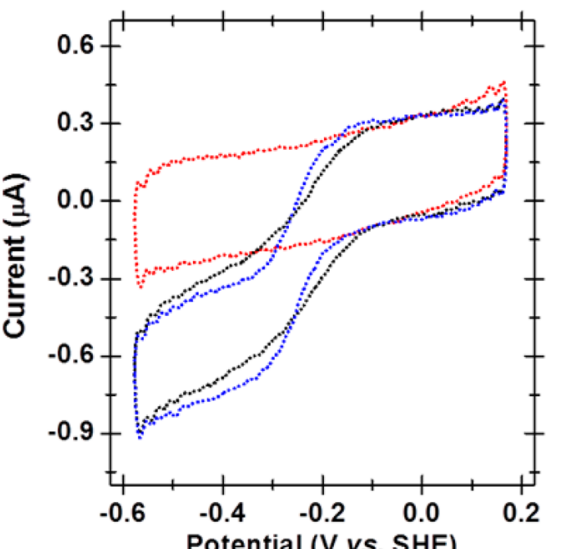

(c) $6^{\text {th }}$ harmonic

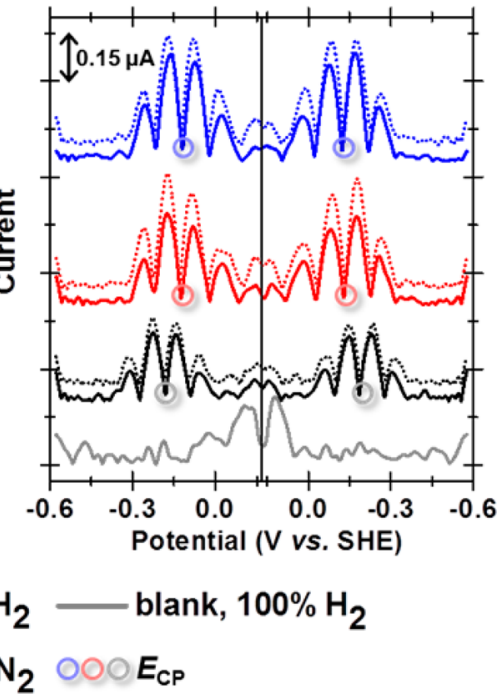

Figure 2. FTacV of E. coli hydrogenase-1 at frequency $=144 \mathrm{~Hz}$, amplitude $=150 \mathrm{mV}$, and scan rate $=27.94 \mathrm{mV} \mathrm{s}^{-1}$. (a and b) Aperiodic dc component of forward and reverse scans shown as cyclic voltammograms. (c) Sixth-harmonic components of forward and reverse scan. Data sets are offset for clarity, and color code is as indicated, where "blank" refers to an enzyme-free control experiment. Other experimental conditions: $\mathrm{pH}$ 4.0, $2000 \mathrm{rpm}, 25^{\circ} \mathrm{C}$.

and the positively charged Arg side chain (Figure 1a and Supplementary Figure 2). ${ }^{30,31}$ Such interactions have recently been identified as playing a vital role in tuning protein redox chemistry involving Trp residues, ${ }^{32-35}$ and we have explored how an E. coli Hyd-1 small subunit Arg-193 to Leu amino acid exchange (HyaA-R193L) impacts $E_{\text {dist }}$ and what the associated catalytic changes are. First coordination sphere ligands are not investigated, as the only previous study on distal cluster variants of a $[\mathrm{NiFe}]$-hydrogenase showed that in the $\mathrm{O}_{2}$-sensitive Desulfovibrio fructosovorans enzyme changing the Fe-ligating His residue to a Gly or Cys had a strikingly deleterious effect on catalysis $\left(\mathrm{H}_{2}\right.$ oxidation activity decreased by at least $\left.97 \%\right){ }^{36}$ Recent density functional theory calculations suggest that this is because electrons pass between the outer surface of the protein and the distal cluster via a precise molecular route that terminates at the His ligand (Supplementary Figure 1). ${ }^{37,38}$ Variants HyaA-K189N and HyaA-Y191E, which mimic differences in this surface-to-histidine route in $\mathrm{O}_{2}$-tolerant and $\mathrm{O}_{2}$ sensitive $[\mathrm{NiFe}]$-hydrogenases (Figure 1 ), are generated to investigate the role of residues along this route in tuning $E_{\text {dist. }}$.

EPR measurements do not provide a measure of $E_{\text {dist }}$ for the genetically tractable enzyme $E$. coli $\mathrm{Hyd}-1$ because the distal center is EPR-silent or -invisible in the oxidized $\left[\mathrm{Fe}_{4} \mathrm{~S}_{4}\right]^{2+}$ and reduced $\left[\mathrm{Fe}_{4} \mathrm{~S}_{4}\right]^{1+}$ states, respectively. ${ }^{27}$ Traditional directcurrent voltammetry measurements cannot be used to probe $E_{\text {dist }}$ because such experiments require noncatalytic conditions, ${ }^{39}$ but protons cannot be excluded from aqueous solutions. Although $\mathrm{CO}$ is a competitive inhibitor of $E c$ Hyd1 , causing partial inhibition, ${ }^{4}$ under an atmosphere of $100 \%$ CO the catalytic activity of an $\mathrm{O}_{2}$-tolerant hydrogenase cannot be fully inhibited, ${ }^{40,41}$ and the enzyme generates enough $\mathrm{H}_{2}$ to yield a measurable oxidation current. Computational modeling of the protein structure cannot provide a value for $E_{\text {dist }}$ via direct calculation because the assignment of the electronic levels in iron sulfur clusters is extremely challenging, and such estimates are normally calibrated against unambiguous experimental data. ${ }^{42}$ Therefore, in order to provide the first measure of $E_{\text {dist }}$, we use large-amplitude Fourier-transformed alternating current voltammetry ${ }^{43}$ (FTacV) to probe a hydrogenase for the first time.

In FTacV a large-amplitude sine wave of frequency $f$ is applied to a voltage sweep and the measured current output is Fourier transformed into the frequency domain to give an aperiodic direct current $(\mathrm{dc})$ component and harmonic signals at multiples of the input frequency $(f, 2 f$, etc.). Individual harmonics are band selected and inverse Fourier transformed back to the time domain. ${ }^{43-45}$ This is advantageous because in one experiment an $\mathrm{FTacV}$ measurement of a redox enzyme and substrate can simultaneously quantify (i) the catalytic current (via the aperiodic dc component) and (ii) noncatalytic, reversible electron transfer processes, such as the distal cluster redox transition $\left[\mathrm{Fe}_{4} \mathrm{~S}_{4}\right]^{2+71+}$, via the capacitance-free high harmonic current. ${ }^{45}$ Thus, unlike traditional voltammetry techniques, in FTacV catalytic current does not mask noncatalytic current, and we describe how this allows us to quantify turnover rates. Complementary EPR experiments probe the redox chemistry of iron-sulfur sites not interrogated via FTacV. We detail the mechanism of how the single HyaAR193L amino acid exchange enhances bias toward $\mathrm{H}_{2}$ production and reduces the $\mathrm{H}_{2}$ oxidation overpotential for an $\mathrm{O}_{2}$-tolerant $[\mathrm{NiFe}]$-hydrogenase and show that the variant enzyme retains catalytic activity in the presence of $\mathrm{O}_{2}$ with slightly diminished tolerance.

\section{RESULTS}

Separate Resolution of Hydrogenase Catalytic and Noncatalytic Processes by FTacV. The aperiodic dc and sixth harmonic ac components of high-frequency $(144 \mathrm{~Hz})$ and large-amplitude $(150 \mathrm{mV}) \mathrm{FTacV}$ conducted on as-isolated E. coli Hyd-1 adsorbed on a graphite electrode are shown in Figure 2, along with enzyme-free "blank" control data. For native enzyme, the aperiodic dc component is analogous to previous direct current voltammetry $(\mathrm{dcV})$ studies; thus at $\mathrm{pH}$ 4.0 negative current corresponding to $\mathrm{H}_{2}$ production $\left(\mathrm{H}^{+}\right.$ reduction) catalysis is detectable under $100 \% \mathrm{~N}_{2}$, but under $100 \% \mathrm{H}_{2}$ only positive current from $\mathrm{H}_{2}$ oxidation catalysis is 
measured. ${ }^{2}$ The higher order harmonic signals from the same experiments (displayed as current magnitude plots for the sixth harmonic in Figure 2) are insensitive to the presence of $\mathrm{H}_{2}$, indicating that the $\mathrm{FTacV}$ technique has enabled the simultaneous and separate measurement of noncatalytic electron transfer in the high harmonics and catalytic current in the aperiodic dc component. For clarity, only the sixth harmonic is depicted in Figure 2, but harmonics 4-7 all provide a background-free measurement of noncatalytic enzyme redox chemistry, Supplementary Figure 3. FTacV conducted at higher $\mathrm{pH}$ shows a negative shift in the potential at which a signal is detected in the high-order harmonics and the expected drop in $\mathrm{H}_{2}$ production current in the aperiodic $\mathrm{dc}$ component (Supplementary Figure 4). The amplitude of the sine wave utilized in FTacV affects the apparent onset potential of catalysis in the aperiodic dc component ${ }^{46}$ (Supplementary Figure 5), so catalytic overpotential values are assessed in separate $\mathrm{dcV}$ experiments described later.

To experimentally corroborate the separate resolution of catalytic and noncatalytic redox processes in $144 \mathrm{~Hz} \mathrm{FTacV}$ of as-isolated native Hyd-1, a catalytically disabled HyaB-E28Q variant was generated, with the fully conserved proton transfer residue close to the $\mathrm{NiFe}$ center (Figure 1) replaced by a nonacidic residue, as first described for $D$. fructosovorans $[\mathrm{NiFe}]$-hydrogenase. ${ }^{19}$ The structural integrity of the medial and proximal clusters of HyaB-E28Q was confirmed by EPR measurements (Supplementary Figures 6 and 7), and the catalytic inactivity was established via $\mathrm{H}_{2}$ oxidation dye assays (Supplementary Figure 8). The aperiodic dc component of 144 $\mathrm{Hz} \mathrm{FTacV}$ of as-isolated HyaB-E28Q further validates the catalytic inactivity, since there is no discernible $\mathrm{H}_{2}$ production current under $100 \% \mathrm{~N}_{2}$ or oxidation current under $100 \% \mathrm{H}_{2}$, at pH 4.0 (Figure 2) or higher pH (Supplementary Figure 9). In contrast, the sixth harmonic of $144 \mathrm{~Hz} \mathrm{FTacV}$ measurements of HyaB-E28Q and native Hyd-1 are almost identical under both $100 \% \mathrm{~N}_{2}$ and $\mathrm{H}_{2}$ (Figure 2 and Supplementary Figure 9), confirming that such high-frequency harmonics provide a measure of purely noncatalytic hydrogenase electron transfer current.

Lower frequency $(9 \mathrm{~Hz}) \mathrm{FTacV}$ measurements of native enzyme do not provide this full separation of catalytic and noncatalytic current. The sixth harmonic of an $8.98 \mathrm{~Hz} \mathrm{FTacV}$ measurement of native $\mathrm{Hyd}-1$ is sensitive to $\mathrm{H}_{2}$ (Supplementary Figure 10) and no longer matches that of the inactive HyaB-E28Q (Supplementary Figure 11), indicating a catalytic component to the high harmonic current. ${ }^{46}$ Theoretical simulations have previously predicted that for a sufficiently rapid surface-confined catalytic process $\mathrm{FTacV}$ will be unable to deconvolute current contributions from reversible electron transfer and substrate turnover. ${ }^{46}$ To ensure that our maximum experimental frequency of $144 \mathrm{~Hz}$ is always fast enough to generate catalysis-free high harmonic current, as-isolated rather than fully activated Hyd-1 is used for all electrochemical experiments in this study. The catalytic current is lower for asisolated Hyd-1 because following aerobic purification a proportion of the hydrogenase molecules contain catalytically inactivated $\mathrm{Ni}$ sites, which recover activity only upon prolonged (>12 h) exposure to $\mathrm{H}_{2}$ (Supplementary Figure 8).,20,22

Assignment of the High-Order Harmonic Signal to Distal Cluster Redox Chemistry. An automated parameter optimization procedure can be used to determine the values that give the best fit between a model redox reaction and high harmonic FTacV data measured at a low frequency. ${ }^{44}$ The 8.88
$\mathrm{Hz}$ FTacV measurements of HyaB-E28Q are uncomplicated by any catalytic reactions and were therefore simulated using such a protocol, resulting in a good fit between the experimental data and a model reversible one-electron redox reaction. This yields a measure of the total amount of protein on the electrode, $M=$ 0.195 pmol, and making the usual allowances for a geometric surface area of $0.03 \mathrm{~cm}^{2}$ yields a coverage of $6.5 \mathrm{pmol} \mathrm{cm}$, entirely consistent with the $3-12 \mathrm{pmol} \mathrm{cm}^{-2}$ range of coverages observed in the electrochemical study of Allochromatium vinosum $\mathrm{O}_{2}$-sensitive $[\mathrm{NiFe}]$-hydrogenase by Pershad et al. ${ }^{39}$

Since this is a surface-confined process, we have simulated the problem without including any terms for electrode rotation. Full reversibility is achieved in the model by setting $k^{0}$ sufficiently high; in this case we fix $k^{0}$ at $10^{4} \mathrm{~s}^{-1}$ (which is equivalent to using the Nernst equation at this low frequency). In this low-frequency regime it would not be possible to detect the distribution in $k^{0}$ values, which is predicted by previous models of hydrogenase catalytic wave shapes. $5,23,25,26,47$ In studies of single molecules of the copper metalloprotein azurin, a Gaussian distribution of $E^{0}$ values has been experimentally observed, ${ }^{48-51}$ and we find that incorporation of such thermodynamic distribution is necessary to yield the good fit shown in Figure 3 between the simulation and experimental data (see Supplementary Figure 12). The best fit potential values are average $E_{\text {rev }}=-123 \mathrm{mV}$, and standard deviation $=31$ $\mathrm{mV}$.

Except for a scalar increase in magnitude, FTacV measurements of HyaB-E28Q at frequencies greater than $8.88 \mathrm{~Hz}$ yield sixth-harmonic signals with a very similar current response, indicating that the same redox process is under interrogation (Supplementary Figure 13). The center point potential of the $144 \mathrm{~Hz}$ high harmonic signals, $E_{\mathrm{CP}}$ (the potential of the minimum and maximum current in the center of the even and odd harmonic signals, respectively), corresponds to the simulation-derived average redox potential $E_{\text {rev }}$ (Figures 2 and 3). Therefore, $E_{\mathrm{CP}}$, derived from simple inspection of the 144 $\mathrm{Hz} \mathrm{FTacV} \mathrm{data,} \mathrm{is} \mathrm{used} \mathrm{as} \mathrm{a} \mathrm{measure} \mathrm{of} \mathrm{the} \mathrm{midpoint} \mathrm{potential}$ of the one-electron transfer redox reaction ascribed as giving rise to the noncatalytic current. Since the $144 \mathrm{~Hz} \mathrm{FTacV} \mathrm{high}$ harmonics of native Hyd-1 and HyaB-E28Q are almost identical (Figure 2), the same $E_{\mathrm{CP}}$ analysis is applied to highfrequency measurements of native Hyd-1 (Supplementary Figure 3). Between $\mathrm{pH} 3$ and 7 the $E_{\mathrm{CP}}$ of native Hyd-1 and HyaB-E28Q remains essentially indistinguishable, both decreasing as a function of $\mathrm{pH}$ with a gradient of $-18 \mathrm{mV} \mathrm{pH}^{-1}$ (Supplementary Figure 14 and Supplementary Table 1).

Since the $144 \mathrm{~Hz}$ FTacV high-harmonic signal of as-isolated native Hyd-1 is insensitive to $\mathrm{H}_{2}$ and carbon monoxide, an inhibitor that is known to bind at the active site of $[\mathrm{NiFe}$ hydrogenases $^{1,4}$ (Supplementary Figure 15), it is unlikely that this current arises from Ni-based redox chemistry. Comparison of $E_{\mathrm{CP}}$ values with the published potentials of E. coli Hyd-1 active site $\mathrm{Ni}$ redox transitions ${ }^{22,52,53}$ validates this assignment, indicating that the noncatalytic FTacV current must instead arise from iron-sulfur cluster chemistry (Supplementary Table 2 and associated text).

For native Hyd-1 at $\mathrm{pH} 7.0$ the EPR-titration-determined midpoint potentials of the proximal and medial iron-sulfur cluster redox transitions are positive (Supplementary Figure 16 and Supplementary Table 3), while $E_{\mathrm{CP}}=-176 \pm 3 \mathrm{mV}$ (Supplementary Table 1). This suggests that it is the EPRinvisible ${ }^{27}$ distal cluster redox transition, $\left[\mathrm{Fe}_{4} \mathrm{~S}_{4}\right]^{2+/ 1+}$, under interrogation in the $144 \mathrm{~Hz}$ FTacV high harmonics. We cannot 


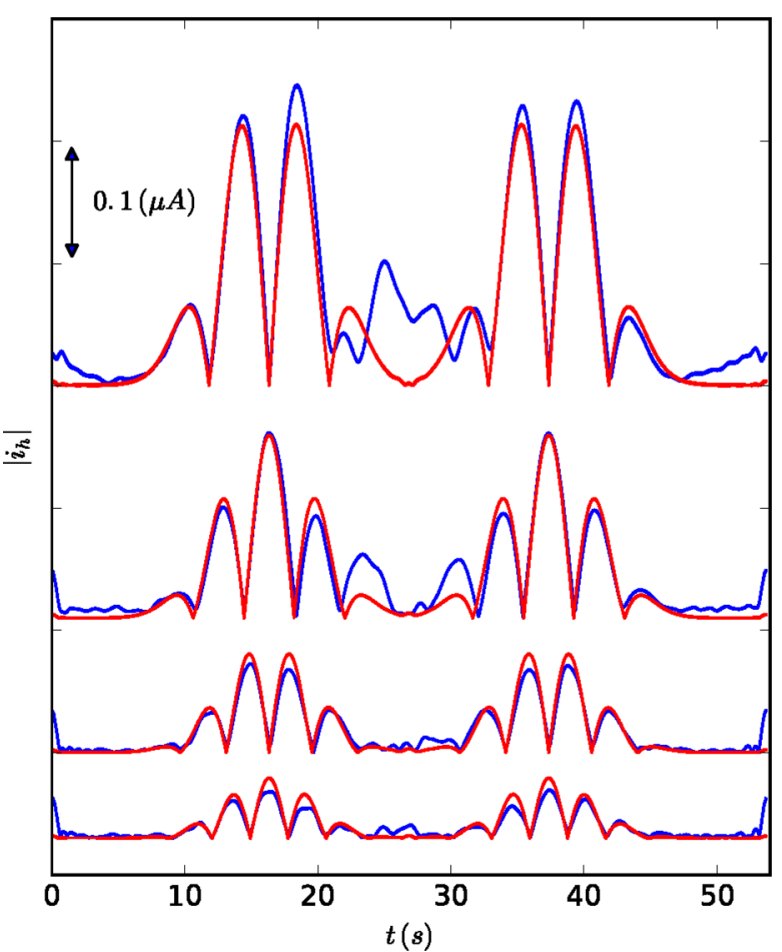

Figure 3. Simulation of HyaAB-E28Q FTacV. Overlay of the absolute current magnitudes of the 4th (top) to 7th (bottom) harmonic components of $8.88 \mathrm{~Hz} \mathrm{FTacV}$ experimental measurement of HyaB$\mathrm{E} 28 \mathrm{Q}$ (blue) and parameter-optimized reversible one-electron reaction simulation (red), as detailed in the text. Each plot was obtained by (i) filtering out the positive frequencies of each harmonic in the frequency domain, (ii) frequency-shifting these down to a center frequency of zero, and then (iii) taking the inverse Fourier transform. Other experimental conditions: amplitude $=150 \mathrm{mV}$, scan rate $=27.94 \mathrm{mV}$ $\mathrm{s}^{-1}, \mathrm{pH} 4.0,100 \% \mathrm{H}_{2}$ atmosphere, $2000 \mathrm{rpm}, 25^{\circ} \mathrm{C}$, uncompensated resistance $\left(R_{\mathrm{u}}\right)=20 \Omega$. Simulation parameters: phase $=-0.0327$, average $E_{\text {rev }}=-0.123 \mathrm{~V}$ with std dev $=0.031 \mathrm{~V}, \Gamma=6.5 \mathrm{pmol} \mathrm{cm}{ }^{-2}$.

measure across a wider potential window in an attempt to also observe current from the medial and proximal cluster redox transitions because the graphite electrode surface ceases to be nonreactive, with faradaic responses attributed to quinone reactivity ${ }^{54}$ observed in enzyme-free "blank" high harmonic FTacV measurements (Supplementary Figure 17).

A HyaA-R193L variant was designed to disrupt the putative cation $-\pi$ interaction between Arg-193 and the distal cluster His-ligand of E. coli Hyd-1 (Figure 1). The $144 \mathrm{~Hz} \mathrm{FTacV} \mathrm{sixth}$ harmonic of HyaA-R193L is insensitive to $\mathrm{H}_{2}$ and retains the same shape as native Hyd-1 and HyaB-E28Q (Figure 2 and Supplementary Figure 9), suggesting that a one-electron noncatalytic redox reaction is again measured. However, because of the amino acid exchange, across the $\mathrm{pH}$ range 3 to 7 the $E_{\mathrm{CP}}$ shifts by approximately $-60 \mathrm{mV}$ relative to native Hyd-1 and HyaB-E28Q (Figure 2 and Supplementary Figures 9 and 14). We interpret this as further evidence that the distal cluster $\left[\mathrm{Fe}_{4} \mathrm{~S}_{4}\right]^{2+/ 1+}$ transition is under interrogation, and from this point it is assumed that $E_{\mathrm{CP}}$ values are equivalent to $E_{\text {dist }}$.

Relating the Distal Cluster Potential to Catalytic Bias and Overpotential. Having determined that FTacV permits measurement of $E_{\text {dist }}$ and generated a variant with a retuned $E_{\text {dist }}$, we now compare the catalytic activity of native Hyd-1 and HyaA-R193L to explore the role of the distal cluster in controlling catalytic bias and overpotential in [NiFe]-hydrogenases. A visual inspection of the aperiodic dc component of $\mathrm{pH} 4.0144 \mathrm{~Hz}$ FTacV (Figure 2) suggests that HyaA-R193L is less biased toward $\mathrm{H}_{2}$ oxidation than native Hyd-1. Under $100 \% \mathrm{~N}_{2}$ the maximum $\mathrm{H}_{2}$ production currents of native $\mathrm{Hyd}-1$ and HyaA-R193L are similar, but under $100 \% \mathrm{H}_{2}$ the $\mathrm{H}_{2}$ oxidation current of HyaA-R193L is significantly lower. A quantitative measure of the changes in turnover rates that led to a change in catalytic bias can only be obtained via knowledge of the number of active moles of enzyme on the electrode, $M_{\text {active }}$. This parameter is normally unmeasurable in the $\mathrm{dcV}$ of $\mathrm{O}_{2^{-}}$ tolerant MBHs. ${ }^{2}$ FTacV permits estimation of $M_{\text {active }}$, and we do so based on $i_{\max }^{144 \mathrm{~Hz}}$, the maximum current magnitude of the $144 \mathrm{~Hz}$ FTacV sixth harmonic. Simulation of $8.88 \mathrm{~Hz} \mathrm{FTacV} \mathrm{of}$ HyaB-E28Q quantified the total amount of hydrogenase on the electrode as $M=0.195 \mathrm{pmol}$ (Figure 3) and when this same protein film was interrogated at $144 \mathrm{~Hz}, i_{\max 6 \mathrm{th}}^{144 \mathrm{~Hz}}=0.285 \mu \mathrm{A}$ (Supplementary Figure 13). For a reversible one-electron reaction the harmonic current magnitude scales linearly with $M{ }^{46}$ so it is extrapolated that $M(\mathrm{~mol}) \approx 6.8 \times 10^{-7} \times i_{\max 6 \text { th }}^{144 \mathrm{~Hz}}$ for all variants. Since as-isolated enzyme is interrogated, some hydrogenase molecules are inactive and $M \neq M_{\text {active }}$. Dye assay (a) $\mathrm{pH} 3,1 \% \mathrm{H}_{2}$

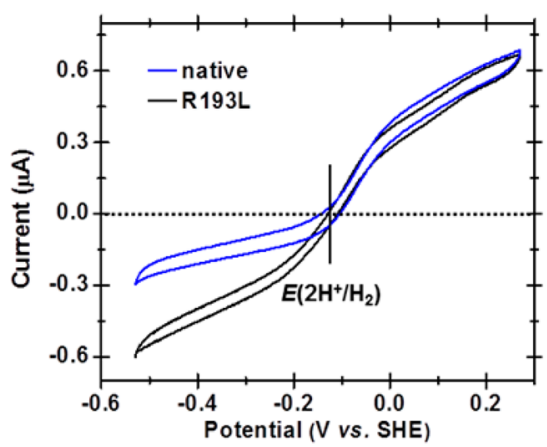

(b) $\mathrm{pH} 7,100 \% \mathrm{H}_{2}$

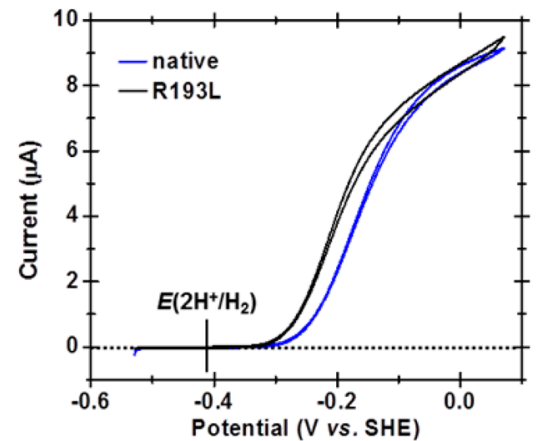

(c) $E_{\mathrm{m}}$ and $E_{c p}$ vs. pH

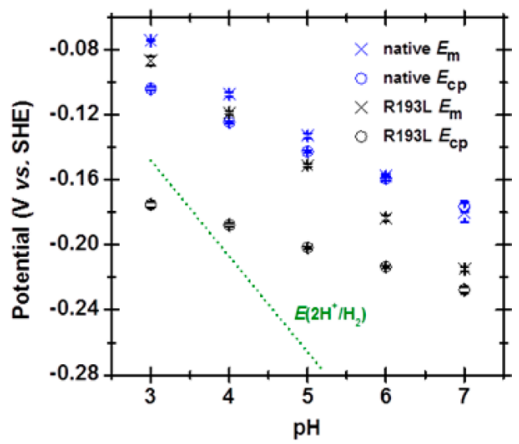

Figure 4. Comparison of the catalytic bias and overpotential requirement of native Hyd-1 and HyaA-R193L. (a) dcV experiment to emphasize increased bias toward $\mathrm{H}_{2}$ production of E. coli hydrogenase-1 HyaA-R193L variant relative to native enzyme. (b) dcV experiment to highlight the decreased catalytic overpotential of HyaA-R193L relative to native Hyd-1. Other experimental conditions: scan rate $=5 \mathrm{mV} \mathrm{s}{ }^{-1}, 25^{\circ} \mathrm{C}, 5000 \mathrm{rpm}$, $\mathrm{pH}$ and gas atmosphere as indicated. (c) $\mathrm{pH}$ dependence of the $\mathrm{H}_{2}$-independent $144 \mathrm{~Hz}$ FTacV determined sixth-harmonic $E_{\mathrm{CP}}, E_{\mathrm{m}}$ from dcV experiments conducted in $10 \% \mathrm{H}_{2}$, and the Nernstian-determined $E\left(2 \mathrm{H}^{+} / \mathrm{H}_{2}\right)$ value at $10 \% \mathrm{H}_{2}$. Error bars show standard error of at least three repeats. 
data indicate that following overnight incubation in $\mathrm{H}_{2}$, activity increases by a scalar factor of approximately 3 for both native Hyd-1 and HyaA-R193L, and so it is estimated that $M_{\text {active }} \approx \frac{M}{3}$ (Supplementary Figure 8).

The turnover rate, $k_{\mathrm{H}_{2}}$, can thus be calculated from a single $144 \mathrm{~Hz}$ FTacV measurement (Figure 2) using the equation $k_{\mathrm{H}_{2}}=\frac{i_{\text {cat }}}{2 M_{\text {active }} F}$, where $F$ is the Faraday constant. ${ }^{39}$ Averaging the catalytic current measured at a certain potential in the forward and back sweep of the aperiodic dc component yields $i_{\text {cat }}$ while $M_{\text {active }}$ is estimated from the sixth harmonic. Analysis of repeat experiments conducted at $\mathrm{pH} 4.0,25{ }^{\circ} \mathrm{C}$, and under $100 \% \mathrm{H}_{2}$ quantifies $\mathrm{H}_{2}$ oxidation turnover rates at $+150 \mathrm{mV}$ of 510,790 , and $750 \mathrm{~s}^{-1}$ for native Hyd-1 and 390, 320, and $190 \mathrm{~s}^{-1}$ for HyaA-R193L. Similarly, $\mathrm{H}_{2}$ production rates at $-550 \mathrm{mV}, \mathrm{pH}$ $4.0,25{ }^{\circ} \mathrm{C}$, and under $100 \% \mathrm{~N}_{2}$ are measured as 45,51 , and 48 $\mathrm{s}^{-1}$ for native Hyd-1 and 75, 60, and $57 \mathrm{~s}^{-1}$ for HyaA-R193L. As has been previously noted for hydrogenases, the electrocatalytic turnover rates exceed those from the solution assays, suggesting that diffusion may play a limiting role when the enzyme is not directly attached to its electron exchange partner. ${ }^{40}$ There is significant variability in the absolute turnover rates extracted, which can be attributed to error in our quantification of $M_{\text {active }}$ but the analysis suggests that HyaA-R193L is more biased toward $\mathrm{H}_{2}$ production catalysis than native enzyme due to a decrease in $\mathrm{H}_{2}$ oxidation rate and a possible increase in $\mathrm{H}_{2}$ production rate.

Catalytic onset potentials are quantified via $\mathrm{dcV}$ experiments (Figure 4). At $\mathrm{pH} 3.0$ and under $1 \% \mathrm{H}_{2}$ both native Hyd-1 and HyaA-R193L have zero overpotential requirement, since both oxidative and reductive catalysis commence at the potential of $E\left(2 \mathrm{H}^{+} / \mathrm{H}_{2}\right)$ (Figure $4 \mathrm{a}$ ). Since the catalysis is reversible, an absolute measure of catalytic bias can be obtained. The ratios of the $\mathrm{H}_{2}$ oxidation current at $+0.13 \mathrm{~V}$ and $\mathrm{H}^{+}$reduction current at $-0.37 \mathrm{~V}$ (both taken from the average of the forward and back sweep) are $3.2 \pm 0.2$ for native Hyd-1 and $1.1 \pm 0.2$ for HyaA-R193L ( \pm indicates standard error of three repeats for different enzyme "films"). The change in bias cannot be attributed to changes in the Michaelis constant $\left(K_{\mathrm{M}}\right)$ or the inhibition constant $\left(K_{\mathrm{I}}\right)$ for $\mathrm{H}_{2}$ (Supplementary Figure 18 and Supplementary Table 4), suggesting that the lowering of $E_{\text {dist }}$ has either directly or indirectly led to a concomitant shift in catalytic bias toward $\mathrm{H}_{2}$ production in HyaA-R193L.

At $\mathrm{pH} 7.0$ and under $100 \% \mathrm{H}_{2}$ both native Hyd-1 and HyaAR193L are unidirectional, $\mathrm{H}_{2}$ oxidation-only catalysts (Figure $4 b$ ). Both enzymes have an overpotential requirement for $\mathrm{H}_{2}$ oxidation, since catalysis does not commence until a potential significantly higher than $E\left(2 \mathrm{H}^{+} / \mathrm{H}_{2}\right)$. The onset of catalysis is clearly shifted to lower potential for HyaA-R193L, making it a more thermodynamically efficient $\mathrm{H}_{2}$ oxidation catalyst than native Hyd-1 and confirming a relationship between $E_{\text {dist }}$ and catalytic overpotential.

To quantify the impact of $\mathrm{pH}$ on the onset potential of $\mathrm{H}_{2}$ oxidation catalysis, $10 \% \mathrm{H}_{2} \mathrm{dcV}$ experiments in which native Hyd-1 and variant HyaA-R193L had similar maximum oxidative currents were analyzed. The onset potential is compared by characterizing a catalytic potential $E_{\mathrm{m}}$, the potential of the maxima in a first derivative $\mathrm{d} i_{\mathrm{av}} / \mathrm{d} E$ vs $E$ plot, where $i_{\mathrm{av}}$ is the average of the forward and back current. Defining this parameter also facilitates comparison between $E_{\text {dist }}$ and the potential of $\mathrm{H}_{2}$ oxidation catalysis. As shown in Figure 4c, at $\mathrm{pH}$ 3.0 both native Hyd-1 and HyaA-R193L are thermodynamically optimized catalysts with similar $E_{\mathrm{m}}$ values close to $E\left(2 \mathrm{H}^{+} / \mathrm{H}_{2}\right)$. Thus, the difference in the $E_{\text {dist }}$ values does not apparently impact the thermodynamic efficiency of catalysis under these conditions. However, as the $\mathrm{pH}$ increases from 3.0 to 7.0, the $E_{\mathrm{m}}$ of HyaA-R193L becomes increasingly more negative than that of native Hyd-1, suggesting that the difference in $E_{\text {dist }}$ values has a significant impact on the overpotential requirement for $\mathrm{H}_{2}$ oxidation under conditions of high $\mathrm{pH}$.

Further Impact of the HyaA-R193L Amino Acid Exchange. Relative to native enzyme, the catalytic profile of HyaA-R193L has been tuned toward that of an $\mathrm{O}_{2}$-sensitive [NiFe]-hydrogenase, with enhanced bias toward $\mathrm{H}_{2}$ production and decreased $\mathrm{H}_{2}$ oxidation overpotential. To examine if $\mathrm{O}_{2}$ tolerance has been maintained following this amino acid exchange, inhibition of $\mathrm{H}_{2}$ oxidation by $3 \% \mathrm{O}_{2}$ in $3 \% \mathrm{H}_{2}$ was quantified using chronoamperometry at $-0.029 \mathrm{~V}, \mathrm{pH} 6.0$, and $25{ }^{\circ} \mathrm{C}$ (Supplementary Figure 19). HyaA-R193L is $\mathrm{O}_{2}$-tolerant, but this tolerance is slightly impaired relative to native Hyd-1; for HyaA-R193L approximately $60 \%$ of initial oxidation activity is sustained in $3 \% \mathrm{O}_{2} / 3 \% \mathrm{H}_{2}$ and approximately $85 \%$ of original activity is rapidly recovered when the $\mathrm{O}_{2}$ is removed; for native Hyd-1 approximately $75 \%$ activity is sustained and approximately $95 \%$ is recovered.

There is also a small difference between HyaA-R193L and native $\mathrm{Hyd}-1$ in the reversible anaerobic formation of the $\mathrm{Ni}-\mathrm{B}$ $(\mathrm{Ni}(\mathrm{III})-\mathrm{OH})$ inactivated state at positive potential. Formation of the $\mathrm{Ni}-\mathrm{B}$ state was achieved via a $1000 \mathrm{~s}$ hold at $+0.451 \mathrm{~V}$, and reactivation was driven by a $0.25 \mathrm{mV} \mathrm{s}^{-1}$ linear sweep to low potential, under $10 \% \mathrm{H}_{2}$ at $25{ }^{\circ} \mathrm{C}$ (Supplementary Figure 20). A qualitative measure of the thermodynamics and kinetics of $\mathrm{Ni}-\mathrm{B}$ reactivation is given by $E_{\text {switch }}$ the potential at which the recovering catalytic current increases most rapidly (potential of the first derivative minima) in the sweep to low potential. $^{55}$ HyaA-R193L has a marginally $(<10 \mathrm{mV})$ more negative $E_{\text {switch }}$ than native $\mathrm{Hyd}-1$ across the $\mathrm{pH}$ range 4.0 to 8.0 (Supplementary Figure 20), indicating slightly slower activation kinetics and/or a slightly more negative $\mathrm{Ni}-\mathrm{B}$ reduction potential. $^{55}$ This difference in $E_{\text {switch }}$ is less than the 15 to 30 $\mathrm{mV}$ difference in $E_{\mathrm{m}}$ (potential of the first derivative maxima) observed in the same experiments (Supplementary Figure 20).

Such changes in anaerobic inactivation and $\mathrm{O}_{2}$ tolerance of E. coli Hyd-1 have previously been related to modifications of the proximal and medial clusters, rather than changes at the distal cluster. ${ }^{20,22}$ EPR titrations at $\mathrm{pH} 7.0$ reveal that the midpoint potentials associated with the medial cluster $[3 \mathrm{Fe} 4 \mathrm{~S}]^{1+/ 0}$ and proximal cluster $\left[\mathrm{Fe}_{4} \mathrm{~S}_{3}\right]^{5+/ 4+}$ redox transitions are more negative in HyaA-R193L than native Hyd-1, decreased by approximately 0.11 and $0.04 \mathrm{~V}$, respectively (Table 1 and Supplementary Figures 21 and 22). Thus, retuning the distal cluster potential also impacts the medial and proximal cluster potentials, indicating a highly convoluted structure-function relationship.

\section{Table 1. EPR-Determined Iron Sulfur Cluster Midpoint} Potentials at $\mathrm{pH} 7.0$

\begin{tabular}{lcc}
\multicolumn{1}{c}{ redox transition } & native Hyd-1 & \\
proximal $\left[\mathrm{Fe}_{4} \mathrm{~S}_{3}\right]^{5+/ 4+}$ & $211 \mathrm{mV}( \pm 15)$ & HyaA-R193L \\
medial $\left[\mathrm{Fe}_{3} \mathrm{~S}_{4}\right]^{1+/ 0}$ & $212 \mathrm{mV}( \pm 30)$ & $103 \mathrm{mV}( \pm 15)$ \\
proximal $\left[\mathrm{Fe}_{4} \mathrm{~S}_{3}\right]^{4+/ 3+}$ & $4 \mathrm{mV}( \pm 15)$ & $-4 \mathrm{mV}( \pm 15)$
\end{tabular}

${ }^{a}$ Errors were estimated by using signal intensities at different field positons ( $g$ values) arising from the same species. 
Distal Cluster Variants HyaA-K189N, HyaA-Y191E, and HyaA-R193E. The variants HyaA-K189N and HyaA-Y191E have the same distal cluster redox potential as native Hyd-1, as quantified by $E_{\mathrm{CP}}$, despite these residues also being in the vicinity of the distal cluster and the amino acid exchanges being inspired by differences between $\mathrm{O}_{2}$-tolerant $\mathrm{MBHs}$ and $\mathrm{O}_{2}$ sensitive $[\mathrm{NiFe}]$-hydrogenases (Figure 1 and Supplementary Figures 23 and 24). The catalytic activity of both variants is also unchanged compared to native enzyme (Supplementary Figures 25 and 26). Attempts were also made to generate a HyaA-R193E variant, to investigate if a distal cluster with even more negative potential would result from replacing the positively charged Arg residue with a negatively charged Glu. However, growth and protein purification from the relevant E. coli mutant did not yield this Hyd-1 variant, suggesting that this amino acid exchange has a deleterious impact on the structural integrity of the enzyme (Supplementary Figure 27).

\section{DISCUSSION}

Using E. coli Hyd-1, we prove that the bias and overpotential of the $2 \mathrm{H}^{+} / \mathrm{H}_{2}$ interconversion that takes place at the buried $\mathrm{NiFe}$ active site of a hydrogenase can be altered by a single amino acid exchange near the distal cluster electron entry/exit site, approximately $30 \AA$ away. Engineering $E_{\text {dist }}$ to a more negative potential correlated with an enhanced bias toward $\mathrm{H}_{2}$ production and decreased overpotential for $\mathrm{H}_{2}$ oxidation, while catalytic activity in the presence of $\mathrm{O}_{2}$ was maintained but with diminished tolerance. [ $\mathrm{NiFe}]$-hydrogenase $\mathrm{H}_{2}$ production activity is important for developing biological and bioinspired solar $\mathrm{H}_{2}$ devices. ${ }^{6,56}$ Decreasing the overpotential in [NiFe]hydrogenase $\mathrm{H}_{2}$ oxidation would also improve the thermodynamic efficiency of fuel cell and $\mathrm{NAD}(\mathrm{P}) \mathrm{H}$ recycling devices which use these enzymes instead of $\mathrm{Pt}^{3,57}$ The previously elusive parameter $E_{\text {dist }}$ is measured using high-frequency, highharmonic FTacV measurements and manipulated via an R193 to $\mathrm{L}$ amino acid exchange that is based on the first proposal of a His-mediated cation $-\pi$ interaction tuning the redox chemistry of an $\mathrm{FeS}$ cluster.

By utilizing FTacV to interrogate Ec Hyd-1 we could work in the frequency domain to analyze our experimental data. This allows us to focus on those parts of the experimental signal that yield a further understanding of electron transfer in/out of the distal cluster, effectively filtering out the catalytic current. We thus derive an FTacV-determined $\mathrm{pH} 7 E_{\text {dist }}$ value of $-176 \mathrm{mV}$ for native Ec Hyd-1. When combined with our EPR-measured proximal cluster $\left[\mathrm{Fe}_{4} \mathrm{~S}_{3}\right]^{4+/ 3+} \mathrm{pH} 7$ midpoint potential of $4 \mathrm{mV}$, this suggests a significant difference in the redox properties of the clusters from the $\mathrm{O}_{2}$-tolerant $[\mathrm{NiFe}]$-hydrogenases of $E_{\mathcal{c}}$ and $A a$. This is in line with known apparent magnetic differences between these centers. The 2011 EPR interrogation of $A a \mathrm{MBH}$ by Pandelia and co-workers reported signals assigned to two different $4 \mathrm{Fe}$ clusters at low potential; the proximal cluster $\left[\mathrm{Fe}_{4} \mathrm{~S}_{3}\right]^{4+/ 3+}$ was assigned a midpoint of +87 $\mathrm{mV}$, and $E_{\text {dist }}$ was measured as $-78 \mathrm{mV}$, both at $\mathrm{pH} 7.4 .^{58,59}$ However, in the $2012 \mathrm{EPR}$ study of $E c \mathrm{Hyd}-1,{ }^{27}$ spin-counting and pulse EPR measurements on native enzyme and three variants established that the distal cluster in this enzyme has a ground state of $S>1 / 2$. The Ec Hyd-1 EPR-visible signal from a $4 \mathrm{Fe}$ cluster at low potential was therefore assigned to the most reduced state of the proximal cluster, ${ }^{27}$ as here. The lack of a structure for the $A a$ enzyme presents a significant barrier in unraveling these striking differences in two enzymes that have similar sequences around the distal cluster.
Cation $-\pi$ interactions between a positively charged amino acid side chain and the $\pi$ system of an aromatic side chain are well documented in structural biology, but much less commonly considered in the tuning of protein redox sites. ${ }^{30}$ In all $\mathrm{O}_{2}$-tolerant $\mathrm{MBH}$ crystal structures an Arg residue points at the distal cluster His ligand with close enough proximity for a cation $-\pi$ interaction to exist. ${ }^{7-12}$ Replacement of the positive Arg residue with a neutral Leu, found in many $\mathrm{O}_{2}$-sensitive $[\mathrm{NiFe}]$-hydrogenases, ${ }^{13-16}$ results in a HyaA-R193L variant with an FTacV-determined $E_{\text {dist }}$ approximately $60 \mathrm{mV}$ more negative than that of native E. coli Hyd-1 across the $\mathrm{pH}$ range 3.0 to 7.0. Thus, removal of the putative electrostatic cation $-\pi$ interaction has increased the thermodynamic driving force required to reduce the distal cluster. This can be rationalized by considering that the cation $-\pi$ interaction serves to withdraw electron density from the cluster in the native enzyme, stabilizing the reduced state. Therefore, cation $-\pi$ interactions should be considered alongside other electrostatic, hydrogenbonding, and hydrophobic interactions in the tuning of protein redox site reduction potentials by secondary coordination sphere effects.

As well as changing $E_{\text {dist }}$, the $\mathrm{R}$ to $\mathrm{L}$ amino acid exchange also impacted the medial and proximal iron-sulfur cluster potentials. Thus, we cannot deconvolute which aspects of the reactivity of HyaA-R193L are solely attributable to the low value of $E_{\text {dist }}$ although it is notable that previous changes to the proximal and medial cluster potentials have had no impact on overpotential or catalytic bias. ${ }^{12,20-22}$ The fact that the redox potential of one center in an electron transfer relay influences the redox potential of other centers is a well-observed phenomenon that has been reported for other [NiFe]hydrogenase variants. ${ }^{19,20,22,27,36}$ Accounting for this interdependency further complicates attempts to computationally model metalloenzyme chemistry and highlights the need for continuing experimentation.

The notion that the catalytic bias of Hyd-1 could be changed by altering $E_{\text {dist }}$ was inspired by the electrocatalytic model of Hexter et al. ${ }^{5,23}$ This simple model predicted a convergence in $E_{\text {dist }}$ and $E\left(2 \mathrm{H}^{+} / \mathrm{H}_{2}\right)$ for native $\mathrm{Hyd}-1$ at low $\mathrm{pH}$, and this is proved. However, the model is not entirely validated; at $\mathrm{pH} 3.0$ and $1 \% \mathrm{H}_{2}$ variant HyaA-R193L is equally biased toward $\mathrm{H}_{2}$ oxidation and production, despite the model predicting more $\mathrm{H}_{2}$ production activity since $E_{\text {dist }}$ is more negative than $E\left(2 \mathrm{H}^{+} /\right.$ $\left.\mathrm{H}_{2}\right)$ (-175 and $-118 \mathrm{mV}$, respectively). ${ }^{5,23}$ Thus, although changes to the catalytic bias can be somewhat correlated with changes to the distal cluster potential, further factors must also control this important enzymatic property. This conclusion is supported by previous studies showing that mutation of amino acid residues distant from the distal cluster can alter the catalytic bias of $[\mathrm{NiFe}]$-hydrogenases. ${ }^{6,60}$ The simple Hexter model implicitly assumes that the distal cluster controls both oxidative and reductive catalysis, but our $\mathrm{pH} 4.0 \mathrm{FTacV}$ rates analyses indicate that the HyaA-R193L amino acid exchange results in a much larger decrease in $\mathrm{H}_{2}$-oxidation rate than increase in $\mathrm{H}_{2}$-production rate. ${ }^{5,23}$ Thus, enzyme wiring appears to play a more vital role in controlling $\mathrm{H}_{2}$ oxidation than $\mathrm{H}_{2}$ production. This supports the more complex model of [NiFe]electrocatalysis proposed by Léger et al., who suggest that the rate of $\mathrm{H}_{2}$ production catalysis is significantly limited by slow $\mathrm{H}_{2}$ release from the active site. ${ }^{25,26}$ Although the simple Hexter model has provided an excellent blueprint for substantially retuning the catalysis of $\mathrm{Hyd}-1$, if the rate of $\mathrm{H}_{2}$ production is 
to be further enhanced, large subunit changes that impact the rate of $\mathrm{H}_{2}$ release from the active site may be required.

The electrocatalytic models of both Hexter et al. ${ }^{5,23}$ and Léger and co-workers ${ }^{25,26}$ also predict a relationship between $E_{\text {dist }}$ and catalytic overpotential that we experimentally validate. At $\mathrm{pH} 7.0$ the difference in the $\mathrm{H}_{2}$ oxidation $E_{\mathrm{m}}$ potentials of native Hyd-1 and variant HyaA-R193L can be very closely correlated to the difference in $E_{\text {dist }}$ values, and HyaA-R193L is a substantially more thermodynamically efficient catalyst (Figure 4). Again, designating $E_{\text {dist }}$ as the sole variable that controls this aspect of electrocatalysis is shown to be an oversimplification of the Hexter model. ${ }^{5,23}$ At $\mathrm{pH} 3.0$ the $E_{\mathrm{m}}$ values of both native Hyd-1 and HyaA-R193L converge, despite the approximately $60 \mathrm{mV}$ difference in $E_{\text {dist }}$ values. Thus, the distal cluster potential is not in total control of the catalytic potential at all pH's, in accordance with the electrocatalytic model of Léger and co-workers, ${ }^{25,26}$ which predicts that both intramolecular and intermolecular electron transfer control catalysis. However, when the potential difference between the substrate potential and that of the electron entry/exit site in the enzyme is sufficiently large, the redox potential of the outermost electron transfer center apparently controls overpotential and, therefore, offers a single point of focus for catalytic retuning strategies.

Conflicting hydrogenase electrocatalysis models exist because large numbers of parameters are required to describe substrate turnover in such complex enzymes. A significant implication of our work is the fact that we determine a lower limit for $k^{0}$, a key electrocatalytic modeling parameter that has been indirectly derived or fitted in all previous hydrogenase electrocatalytic models. ${ }^{3,5,23,25,26,47,61}$ Ongoing work will focus on using FTacV to measure the redox chemistry of the medial and proximal clusters and the distribution in $k^{0}$ that is believed to arise from dispersion in the orientation of enzyme of the electrode surface. ${ }^{47}$ It is only through quantifying such parameters that it will be possible to unambiguously probe the mechanistic origin of the complex voltammetry of hydrogenases.

Nitrogenase, ${ }^{62}$ carbon monoxide dehydrogenase, ${ }^{63}$ and Photosystem $\mathrm{II}^{64}$ enzymes also convert small molecules into their redox-activated and chemically useful counterparts $\left(\mathrm{N}_{2}\right.$ to $\mathrm{NH}_{3}, \mathrm{CO}_{2}$ to $\mathrm{CO}$, and $\mathrm{H}_{2} \mathrm{O}$ to $\mathrm{O}_{2}$, respectively) and contain a relay of redox-active centers that wire the outer surface of the protein to the "buried" active sites. FTacV should be considered a very useful tool for probing such systems and exploring how the electron transfer centers control catalysis in these redox enzymes. Ultimately, the inclusion of a molecular wire may be found to be an important design principle for synthetic multielectron redox catalysts, which typically lack such additional redox centers.

\section{EXPERIMENTAL SECTION}

Molecular Biology. All native and variant Hyd-1 enzymes were produced from W3110-derived E. coli K-12 strain LAF003 and variant strains. Strain LAF003 has an engineered hyaA $\left(h i s_{7}\right) B C D E F$ operon to produce "wild-type" E. coli hydrogenase-1 with a polyhistidine tag at the $\mathrm{C}$ terminus of the small subunit. ${ }^{60}$ Five variant strains, carrying chromosomal hyaB(E28Q), hyaA(R193L), hyaA(R193E), hy$a A(\mathrm{~K} 189 \mathrm{~N})$, and hyaA(Y191E) mutations, were derived from LAF003 using the "counter-selection BAC modification kit" (Cambio) and the protocol detailed previously. ${ }^{60}$ Briefly, the rpsL-neo cassette was inserted into an appropriate region of hyaB or hyaA of strain LAF003 to generate strains HA001 and HA002, respectively. The cassette was swapped out of HA001 by linear DNA (HyaBE28Qdsfrag), to give strain HA003 encoding a chromosomal E28Q mutation in hyaB. The cassette was swapped out of HA002 by linear DNA to give strains HA004, HA005, HA011, and HA014 encoding chromosomal mutations R193L, R193E, K189N, or Y191E, respectively, in hyaA. All mutations were confirmed by sequencing (GATC Biotech). Details of all strains, oligonucleotide primers, plasmids, and linear DNA used in this study are given in Supplementary Tables 5-8.

Protein Production and Purification. All strains were grown and proteins produced using a similar protocol to that detailed previously. ${ }^{60}$ Briefly, strains were cultured anaerobically, harvested at stationary phase, lysed by osmotic shock then sonication, and solubilized overnight by addition of $3 \%$ TritonX-100. Solubilized protein was purified by adding $50 \mathrm{mM}$ imidazole and loading onto a 5 $\mathrm{mL}$ HiTrap $\mathrm{Ni}$ affinity column (GE Healthcare) that had been equilibrated in $20 \mathrm{mM}$ Tris, $150 \mathrm{mM} \mathrm{NaCl}$, and $50 \mathrm{mM}$ imidazole, $\mathrm{pH}$ 7.3. Protein was eluted from the column using step changes in imidazole, up to a maximum concentration of $1 \mathrm{M}$, with all other buffer components unchanged. Fractions containing hydrogenase were confirmed by SDS-PAGE, pooled, and then dialyzed in a $20 \mathrm{mM}$ Tris and $150 \mathrm{mM} \mathrm{NaCl}, \mathrm{pH} 7.3$, buffer overnight at $4{ }^{\circ} \mathrm{C}$ using $6-8 \mathrm{kDa}$ MWCO dialysis tubing (Fisher). Protein was concentrated using a 50 $\mathrm{kDa}$ MWCO Vivaspin centrifugal concentrator (GE Healthcare), and purity was confirmed by SDS-PAGE (Supplementary Figures 28 and 29).

For EPR samples the protein was then dialyzed in $50 \mathrm{mM}$ HEPES, $50 \mathrm{mM}$ dibasic sodium phosphate, $150 \mathrm{mM} \mathrm{NaCl}$, and $30 \% \mathrm{v} / \mathrm{v}$ glycerol, pH 7.0, using a $3.5 \mathrm{kDa}$ MWCO Slide-A-Lyzer cassette (ThermoFisher).

For all assay and electrochemical experiments the protein was further purified by gel filtration on a Superdex 200 10/30 column (GE Healthcare) equilibrated in $20 \mathrm{mM}$ Tris and $150 \mathrm{mM} \mathrm{NaCl}, \mathrm{pH} 7.3$. Fractions containing completely pure hydrogenase were confirmed by SDS-PAGE, pooled, and concentrated using a $50 \mathrm{kDa}$ MWCO Vivaspin centrifugal concentrator (GE Healthcare). Final sample purity was confirmed by SDS-PAGE (Supplementary Figures 28 and 29), and protein concentrations were measured by Bradford assay.

Protein Film Electrochemistry. All electrochemical experiments $(\mathrm{dcV}$ and $\mathrm{FTacV})$ were performed in an anaerobic glovebox (University of York, Department of Chemistry, Mechanical Workshop). A three-electrode setup of a platinum counter, pyrolytic graphite edge (PGE) working electrode (geometric surface area 0.03 $\mathrm{cm}^{2}$ ) and saturated calomel electrode (SCE) reference electrode was used, with a conversion factor of $E(\mathrm{~V}$ vs $\mathrm{SHE})=E(\mathrm{~V}$ vs $\mathrm{SCE})+0.241$. All electrodes were contained in a water-jacketed and gastight glass cell containing a mixed buffer of $15 \mathrm{mM}$ each of MES, CHES, HEPES, TAPS, and $\mathrm{Na}$ acetate and $2 \mathrm{M} \mathrm{NaCl}$. The temperature was controlled to $25{ }^{\circ} \mathrm{C}$ by a water circulator, and the atmosphere regulated by 100 standard cubic centimeters per minute flow of gas (BOC) of a certain composition by mass flow controllers (Sierra Instruments).

To prepare an enzyme film, the PGE surface was abraded with P1200 sandpaper (Norton), and then $0.5 \mu \mathrm{L}$ of a $0.25-1.5 \mathrm{mg} \mathrm{mL}^{-1}$ protein applied to the electrode surface for $\sim 30 \mathrm{~s}$, before excess enzyme was removed with a stream of water (Purlte, $7.4 \mathrm{M} \Omega \cdot \mathrm{cm}$ ). An Origatrod rotator (Origalys) was used to rotate the working electrode at $2000-5000 \mathrm{rpm}$ to ensure mass transport of substrate or product was not rate limiting to catalysis. Direct current cyclic voltammetry and chronoamperometry measurements were performed with an Ivium CompactStat potentiostat. All Fourier-transformed ac voltammetry was performed using the custom-made instrumentation described previously. ${ }^{43}$ Impedance was measured at potentials devoid of Faradaic current, and a simple RC circuit model was used to calculate the uncompensated resistance value used in simulations.

Simulations. Simulations were performed using a protocol based on those previously described in Morris et al. ${ }^{51}$ and Adamson et al. ${ }^{44}$ We assumed a Langmuir isotherm, and any proton transfer accompanying electron transfer is reversible, with the equilibrium constants associated with protonation incorporated into $E_{\text {rev }}$. More details are provided in the Supporting Information.

EPR. EPR titrations were performed as detailed previously. ${ }^{60,65}$ Briefly, $100-200 \mu \mathrm{L}$ of enzyme solution in $\mathrm{pH} 7.0$ buffer (above) was transferred to a custom electrochemical cell with a platinum working 
electrode and $\mathrm{Ag} / \mathrm{AgCl}$ reference electrode (3 $\mathrm{M} \mathrm{KCl}$, DRIREF-2, WPI) inside a Braun UniLab-plus glovebox $\left(\mathrm{O}_{2}<0.5 \mathrm{ppm}, \mathrm{N}_{2}\right.$ atmosphere). The following redox mediators were added to a final concentration of $25 \mu \mathrm{M}$ (native Hyd-1 and HyaB-E28Q) or $40 \mu \mathrm{M}$ (HyaA-R139L): phenazine methosulfate, 1,4-naphthoquinone, methylene blue, indigo trisulfonate, 2-hydroxy-1,4-naphthoquinone, benzyl viologen, and methyl viologen. In addition, $40 \mu \mathrm{M}$ anthraquinine-2sulfonate was added to the HyaA-R139L sample. Each hydrogenase sample was titrated by the addition of small aliquots of potassium ferricyanide or sodium dithionite until the desired potential was achieved, at which stage $9 \mu \mathrm{L}$ samples were transferred to quartz EPR tubes (1.6 mm outer diameter, Wilmad) and flash frozen in ethanol cooled externally using a dry ice/acetone bath.

EPR measurements were performed on an X/Q-band Bruker Elexsys E580 spectrometer (Bruker BioSpin GmbH, Germany) equipped with a closed-cycle cryostat (Cryogenic Ltd., UK) and an $\mathrm{X}$-band split-ring resonator module with $2 \mathrm{~mm}$ sample access (ER 4118X-MS2, Bruker) operated in continuous-wave mode. All measurements were conducted at $20 \mathrm{~K}$ with $2 \mathrm{~mW}$ power, $100 \mathrm{kHz}$ modulation frequency, and $1.0 \mathrm{mT}$ modulation amplitude. In order to determine reduction potentials of the EPR-visible clusters, signal intensities were monitored as a function of potential ("Nernst plots" in Supplementary Figures 16 and 21 ). The proximal $\left[\mathrm{Fe}_{4} \mathrm{~S}_{3}\right]^{5+/ 4+}$ signal intensity was plotted using the difference in peak heights at $g=1.981$ and 1.970 , with the maximum intensity scaled to 1 . The $\left[\mathrm{Fe}_{4} \mathrm{~S}_{3}\right]^{4+/ 3+}$ intensities were taken from the height of the EPR signal at $g=1.892-$ 1.871. The intensity of the medial $\left[\mathrm{Fe}_{3} \mathrm{~S}_{4}\right]^{1+}$ cluster EPR signal (that decreased at high potentials due to magnetic coupling with $\left[\mathrm{Fe}_{4} \mathrm{~S}_{3}\right]^{5+}$ ) was monitored using $g=2.025-1.981$ (native Hyd-1) or $g=2.059-$ 2.025 (HyaA-R193L). The reduction potential of the medial cluster $\left[\mathrm{Fe}_{3} \mathrm{~S}_{4}\right]^{+/ 0}$ transition was determined as described in Roessler et al. ${ }^{27}$ The double integral of the EPR spectrum from the most oxidized sample was normalized to two spins per enzyme molecule to account for the fully oxidized medial and proximal clusters. The percentage of signal arising from the medial cluster was then determined by subtraction of the percentage of signal arising from the proximal cluster (established from its reduction potential). Signal intensities from the medial $[3 \mathrm{Fe}-4 \mathrm{~S}]^{+}$signal were then scaled according to the percentage reduction of the cluster.

\section{ASSOCIATED CONTENT}

\section{S Supporting Information}

The Supporting Information is available free of charge on the ACS Publications website at DOI: 10.1021/jacs.7b03611.

Additional information (PDF)

\section{AUTHOR INFORMATION}

\section{Corresponding Author}

*alison.parkin@york.ac.uk

\section{ORCID}

Alison Parkin: 0000-0003-4715-7200

\section{Present Address}

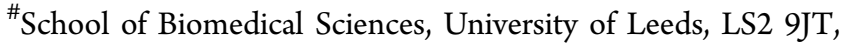
UK.

\section{Notes}

The authors declare no competing financial interest.

\section{ACKNOWLEDGMENTS}

The research leading to these results has received funding from the Royal Society (International Exchange Grant to H.A., A.M.B., and A.P.); BBSRC (studentship BB/F017316/1 to H.A.); Australian Research Council (Discovery Project DP170101535 to A.M.B., D.J.G., and A.P.); EPSRC ("2020 Science" funded through Cross-Disciplinary Interface Programme EP/I017909/1 to M.R. and D.J.G., studentship EP/
M506394/1 to J.J.W., and First Grant EP/M024393/1 to M.M.R.); Wellcome Trust (Combating Infectious Disease: Computational Approaches in Translational Science (WT095024MA) studentship to L.A.F.); and the University of York (J.W. and A.P.).

\section{REFERENCES}

(1) Lubitz, W.; Ogata, H.; Rüdiger, O.; Reijerse, E. Chem. Rev. 2014, 114 (8), 4081-4148.

(2) Flanagan, L. A.; Parkin, A. Biochem. Soc. Trans. 2016, 44 (1), 315-328.

(3) Armstrong, F. A.; Evans, R. M.; Hexter, S. V.; Murphy, B. J.; Roessler, M. M.; Wulff, P. Acc. Chem. Res. 2016, 49 (5), 884-892.

(4) Lukey, M. J.; Parkin, A.; Roessler, M. M.; Murphy, B. J.; Harmer, J.; Palmer, T.; Sargent, F.; Armstrong, F. A. J. Biol. Chem. 2010, 285 (6), 3928-3938.

(5) Hexter, S. V.; Grey, F.; Happe, T.; Climent, V.; Armstrong, F. A. Proc. Natl. Acad. Sci. U. S. A. 2012, 109 (29), 11516-11521.

(6) Raleiras, P.; Khanna, N.; Miranda, H.; Meszaros, L. S.; Krassen, H.; Ho, F.; Battchikova, N.; Aro, E.-M.; Magnuson, A.; Lindblad, P.; Styring, S. Energy Environ. Sci. 2016, 9 (2), 581-594.

(7) Evans, R. M.; Brooke, E. J.; Wehlin, S. A. M.; Nomerotskaia, E.; Sargent, F.; Carr, S. B.; Phillips, S. E. V.; Armstrong, F. A. Nat. Chem. Biol. 2016, 12 (1), 46-50.

(8) Fritsch, J.; Scheerer, P.; Frielingsdorf, S.; Kroschinsky, S.; Friedrich, B.; Lenz, O.; Spahn, C. M. T. Nature 2011, 479 (7372), 249-252.

(9) Shomura, Y.; Yoon, K.-S.; Nishihara, H.; Higuchi, Y. Nature 2011, 479 (7372), 253-256.

(10) Volbeda, A.; Amara, P.; Darnault, C.; Mouesca, J.-M.; Parkin, A.; Roessler, M. M.; Armstrong, F. A.; Fontecilla-Camps, J. C. Proc. Natl. Acad. Sci. U. S. A. 2012, 109 (14), 5305-5310.

(11) Bowman, L.; Flanagan, L. A.; Fyfe, P. K.; Parkin, A.; Hunter, W. N.; Sargent, F. Biochem. J. 2014, 458 (3), 449-458.

(12) Frielingsdorf, S.; Fritsch, J.; Schmidt, A.; Hammer, M.; Löwenstein, J.; Siebert, E.; Pelmenschikov, V.; Jaenicke, T.; Kalms, J.; Rippers, Y.; Lendzian, F.; Zebger, I.; Teutloff, C.; Kaupp, M.; Bittl, R.; Hildebrandt, P.; Friedrich, B.; Lenz, O.; Scheerer, P. Nat. Chem. Biol. 2014, 10 (5), 378-385.

(13) Volbeda, A.; Charon, M.-H.; Piras, C.; Hatchikian, E. C.; Frey, M.; Fontecilla-Camps, J. C. Nature 1995, 373 (6515), 580-587.

(14) Rousset, M.; Montet, Y.; Guigliarelli, B.; Forget, N.; Asso, M.; Bertrand, P.; Fontecilla-Camps, J. C.; Hatchikian, E. C. Proc. Natl. Acad. Sci. U. S. A. 1998, 95 (20), 11625-11630.

(15) Ogata, H.; Kellers, P.; Lubitz, W. J. Mol. Biol. 2010, 402 (2), $428-444$.

(16) Ogata, H.; Nishikawa, K.; Lubitz, W. Nature 2015, 520 (7548), $571-574$.

(17) Gebler, A.; Burgdorf, T.; De Lacey, A. L.; Rüdiger, O.; MartinezArias, A.; Lenz, O.; Friedrich, B. FEBS J. 2007, 274 (1), 74-85.

(18) Greene, B. L.; Vansuch, G. E.; Wu, C.-H.; Adams, M. W. W.; Dyer, R. B. J. Am. Chem. Soc. 2016, 138 (39), 13013-13021.

(19) Dementin, S.; Burlat, B.; De Lacey, A. L.; Pardo, A.; Adryanczyk-Perrier, G.; Guigliarelli, B.; Fernandez, V. M.; Rousset, M. J. Biol. Chem. 2004, 279 (11), 10508-10513.

(20) Lukey, M. J.; Roessler, M. M.; Parkin, A.; Evans, R. M.; Davies, R. A.; Lenz, O.; Friedrich, B.; Sargent, F.; Armstrong, F. A. J. Am. Chem. Soc. 2011, 133 (42), 16881-16892.

(21) Goris, T.; Wait, A. F.; Saggu, M.; Fritsch, J.; Heidary, N.; Stein, M.; Zebger, I.; Lendzian, F.; Armstrong, F. A.; Friedrich, B.; Lenz, O. Nat. Chem. Biol. 2011, 7 (5), 310-318.

(22) Evans, R. M.; Parkin, A.; Roessler, M. M.; Murphy, B. J.; Adamson, H.; Lukey, M. J.; Sargent, F.; Volbeda, A.; Fontecilla-Camps, J. C.; Armstrong, F. A. J. Am. Chem. Soc. 2013, 135 (7), 2694-2707.

(23) Hexter, S. V.; Esterle, T. F.; Armstrong, F. A. Phys. Chem. Chem. Phys. 2014, 16 (24), 11822-11833.

(24) Murphy, B. J.; Sargent, F.; Armstrong, F. A. Energy Environ. Sci. 2014, 7 (4), 1426-1433. 
(25) Fourmond, V.; Baffert, C.; Sybirna, K.; Lautier, T.; Abou Hamdan, A.; Dementin, S.; Soucaille, P.; Meynial-Salles, I.; Bottin, H.; Léger, C. J. Am. Chem. Soc. 2013, 135 (10), 3926-3938.

(26) Abou Hamdan, A.; Dementin, S.; Liebgott, P.-P.; GutierrezSanz, O.; Richaud, P.; De Lacey, A. L.; Rousset, M.; Bertrand, P.; Cournac, L.; Léger, C. J. Am. Chem. Soc. 2012, 134 (20), 8368-8371.

(27) Roessler, M. M.; Evans, R. M.; Davies, R. A.; Harmer, J.; Armstrong, F. A. J. Am. Chem. Soc. 2012, 134 (37), 15581-15594.

(28) Marshall, N. M.; Garner, D. K.; Wilson, T. D.; Gao, Y.-G.; Robinson, H.; Nilges, M. J.; Lu, Y. Nature 2009, 462 (7269), 113-116.

(29) Stephens, P. J.; Jollie, D. R.; Warshel, A. Chem. Rev. 1996, 96 (7), 2491-2514.

(30) Mahadevi, A. S.; Sastry, G. N. Chem. Rev. 2013, 113 (3), 21002138 .

(31) Liao, S.-M.; Du, Q.-S.; Meng, J.-Z.; Pang, Z.-W.; Huang, R.-B. Chem. Cent. J. 2013, 7 (1), 44.

(32) Kobayashi, K.; Mizuno, M.; Fujikawa, M.; Mizutani, Y. Biochemistry 2011, 50 (44), 9468-9474.

(33) Yorita, H.; Otomo, K.; Hiramatsu, H.; Toyama, A.; Miura, T.; Takeuchi, H. J. Am. Chem. Soc. 2008, 130 (46), 15266-15267.

(34) Xue, Y.; Davis, A. V.; Balakrishnan, G.; Stasser, J. P.; Staehlin, B. M.; Focia, P.; Spiro, T. G.; Penner-Hahn, J. E.; O’Halloran, T. V. Nat. Chem. Biol. 2008, 4 (2), 107-109.

(35) Sibert, R.; Josowicz, M.; Porcelli, F.; Veglia, G.; Range, K.; Barry, B. A. J. Am. Chem. Soc. 2007, 129 (14), 4393-4400.

(36) Dementin, S.; Belle, V.; Bertrand, P.; Guigliarelli, B.; Adryanczyk-Perrier, G.; De Lacey, A. L.; Fernandez, V. M.; Rousset, M.; Léger, C. J. Am. Chem. Soc. 2006, 128 (15), 5209-5218.

(37) Petrenko, A.; Stein, M. Int. J. Mol. Sci. 2017, 18 (1), 100.

(38) Petrenko, A.; Stein, M. J. Phys. Chem. B 2015, 119 (43), 1387013882.

(39) Pershad, H. R.; Duff, J. L. C.; Heering, H. A.; Duin, E. C.; Albracht, S. P. J.; Armstrong, F. A. Biochemistry 1999, 38 (28), 89928999.

(40) Vincent, K. A.; Parkin, A.; Armstrong, F. A. Chem. Rev. 2007, 107 (10), 4366-4413.

(41) Vincent, K. A.; Cracknell, J. A.; Lenz, O.; Zebger, I.; Friedrich, B.; Armstrong, F. A. Proc. Natl. Acad. Sci. U. S. A. 2005, 102 (47), 16951-16954.

(42) Sharma, S.; Sivalingam, K.; Neese, F.; Chan, G. K.-L. Nat. Chem. 2014, 6 (10), 927-933.

(43) Bond, A. M.; Elton, D.; Guo, S.-X.; Kennedy, G. F.; Mashkina, E.; Simonov, A. N.; Zhang, J. Electrochem. Commun. 2015, 57, 78-83. (44) Adamson, H.; Robinson, M.; Bond, P. S.; Soboh, B.; Gillow, K.; Simonov, A. N.; Elton, D. M.; Bond, A. M.; Sawers, R. G.; Gavaghan, D. J.; Parkin, A. Anal. Chem. 2017, 89 (3), 1565-1573.

(45) Adamson, H.; Simonov, A. N.; Kierzek, M.; Rothery, R. A.; Weiner, J. H.; Bond, A. M.; Parkin, A. Proc. Natl. Acad. Sci. U. S. A. 2015, 112 (47), 14506-14511.

(46) Zhang, J.; Bond, A. M. J. Electroanal. Chem. 2007, 600 (1), 2334.

(47) Léger, C.; Jones, A. K.; Albracht, S. P. J.; Armstrong, F. A. J. Phys. Chem. B 2002, 106 (50), 13058-13063.

(48) Tabares, L.; Gupta, A.; Aartsma, T.; Canters, G. Molecules 2014, 19 (8), 11660

(49) Salverda, J. M.; Patil, A. V.; Mizzon, G.; Kuznetsova, S.; Zauner, G.; Akkilic, N.; Canters, G. W.; Davis, J. J.; Heering, H. A.; Aartsma, T. J. Angew. Chem., Int. Ed. 2010, 49 (33), 5776-5779.

(50) Davis, J. J.; Burgess, H.; Zauner, G.; Kuznetsova, S.; Salverda, J.; Aartsma, T.; Canters, G. W. J. Phys. Chem. B 2006, 110 (41), 2064920654.

(51) Morris, G. P.; Baker, R. E.; Gillow, K.; Davis, J. J.; Gavaghan, D. J.; Bond, A. M. Langmuir 2015, 31 (17), 4996-5004.

(52) Hidalgo, R.; Ash, P. A.; Healy, A. J.; Vincent, K. A. Angew. Chem., Int. Ed. 2015, 54 (24), 7110-7113.

(53) Murphy, B. J.; Hidalgo, R.; Roessler, M. M.; Evans, R. M.; Ash, P. A.; Myers, W. K.; Vincent, K. A.; Armstrong, F. A. J. Am. Chem. Soc. 2015, 137 (26), 8484-8489.

(54) Lu, M.; Compton, R. G. Analyst 2014, 139 (10), 2397-2403.
(55) Fourmond, V.; Infossi, P.; Giudici-Orticoni, M.-T.; Bertrand, P.; Léger, C. J. Am. Chem. Soc. 2010, 132 (13), 4848-4857.

(56) Mersch, D.; Lee, C.-Y.; Zhang, J. Z.; Brinkert, K.; FontecillaCamps, J. C.; Rutherford, A. W.; Reisner, E. J. Am. Chem. Soc. 2015, 137 (26), 8541-8549.

(57) Reeve, H. A.; Lauterbach, L.; Lenz, O.; Vincent, K. A. ChemCatChem 2015, 7 (21), 3593-3593.

(58) Pandelia, M.-E.; Nitschke, W.; Infossi, P.; Giudici-Orticoni, M.T.; Bill, E.; Lubitz, W. Proc. Natl. Acad. Sci. U. S. A. 2011, 108 (15), 6097-6102.

(59) Pandelia, M.-E.; Bykov, D.; Izsak, R.; Infossi, P.; GiudiciOrticoni, M.-T.; Bill, E.; Neese, F.; Lubitz, W. Proc. Natl. Acad. Sci. U. S. A. 2013, 110 (2), 483-488.

(60) Flanagan, L. A.; Wright, J. J.; Roessler, M. M.; Moir, J. W.; Parkin, A. Chem. Commun. 2016, 52 (58), 9133-9136.

(61) Léger, C.; Bertrand, P. Chem. Rev. 2008, 108 (7), 2379-2438.

(62) Milton, R. D.; Abdellaoui, S.; Khadka, N.; Dean, D. R.; Leech, D.; Seefeldt, L. C.; Minteer, S. D. Energy Environ. Sci. 2016, 9 (8), 2550-2554.

(63) Can, M.; Armstrong, F. A.; Ragsdale, S. W. Chem. Rev. 2014, 114 (8), 4149-4174.

(64) Suga, M.; Akita, F.; Hirata, K.; Ueno, G.; Murakami, H.; Nakajima, Y.; Shimizu, T.; Yamashita, K.; Yamamoto, M.; Ago, H.; Shen, J.-R. Nature 2015, 517 (7532), 99-103.

(65) Wright, J. J.; Salvadori, E.; Bridges, H. R.; Hirst, J.; Roessler, M. M. J. Inorg. Biochem. 2016, 162, 201-206. 